\title{
A comparison of bounding approach with isotopic correction factors and Monte Carlo sampling in burnup credit method
}

\author{
Pavlína Haroková ${ }^{1}$, Martin Lovecký ${ }^{1}$ \\ ${ }^{1}$ Škoda JS a.s., Czech Republic \\ pavlina.harokova@skoda-js.cz
}

\begin{abstract}
One of the methodologies used in criticality safety analysis is burnup credit method, which allows considering fuel burnup in models with spent fuel. This removes excessive conservatism from the analysis, but it also brings new uncertainties originating from computational prediction of spent fuel composition. The burnup credit method offer several possibilities of how to deal with this problem, e.g. using bounding approach with correction factors on nuclide concentrations, which is simple, but still very conservative approach. Another option is Monte Carlo sampling, which aims at receiving the most realistic result as possible, but is very computationally demanding. In this work, we have analyzed correction factors for selected nuclides and compared the results of both methods on model of spent fuel storage pool. The results show how much conservative the bounding approach is - in this case, the multiplication factor was higher by almost 0.03 than in Monte Carlo sampling, exceeding the standard deviation by more than 5.4 times.
\end{abstract}

Keywords -Bounding approach, Monte Carlo sampling, Burnup credit, SCALE

\section{INTRODUCTION}

$\mathrm{W}$ HEN evaluating the nuclear safety of a system, a criticality analysis is performed in order to determine whether the system meets the requirements of the local regulations. The regulation requirements could be summarized in simplified form as:

$$
k_{\text {eff }}+\sum \Delta_{i} \leq k_{\text {limit }}
$$

where $k_{\text {eff }}$ is calculated value of effective multiplication factor of the evaluated model, which should be less than or equal to limit value $k_{\text {limit }}$ (usually defined by legislation), if all biases and uncertainties marked as $\Delta_{i}$ are included.

Burnup credit is an approach that credits the reduction in reactivity due to fuel burnup. The calculation using burnup credit method consists of two main steps: a burnup calculation, which estimates nuclide concentrations in the spent fuel, and criticality calculation, which uses the nuclide concentrations determined in the first step. However, computational prediction of fuel composition introduces an additional source of bias or uncertainty. There are several methods that deal with these uncertainties and in general, they can be divided into two main categories: bounding methods and best-estimate methods.

The bounding approach aims to get the most conservative result by adjusting the concentrations of nuclides in a system. The concentration of selected nuclides in the model is multiplied by correction factors (referred to also as the isotopic correction factors) so that concentrations of fissile nuclides are increased and concentrations of absorbing nuclides are decreased. This leads to a more reactive system with the conservative estimate of multiplication factor $\mathrm{k}_{\mathrm{eff}}$.

The best-estimate methods aim to determine the uncertainty in spent fuel in a more accurate and realistic way. This can be done by using Monte Carlo sampling of the different parameters in a model based on their uncertainty and selected distribution. Other options, such as direct-difference method or sensitivity calculations, are also possible.

In this paper, we have tried to investigate how different the results of both methods are and what impact this could have on the possible compliance with regulatory limits.

\section{CORRECTION FACTORS}

Correction factors $(\mathrm{CF})$ are part of validation of each calculation code. The factors are calculated from difference between the experiment and the calculation $(\mathrm{E} / \mathrm{C})$ based on $\mathrm{PIE}$ experiments results. The mean $\mathrm{E} / \mathrm{C}$ value of a given nuclide is increased or decreased (depending whether it is fissile or absorbing nuclide) by the value of its standard deviation multiplied by the tolerance-limit factor.

The value of tolerance-limit factor is determined by the number of measured samples in PIE experiments. If more than 10 measurement data are available for a nuclide, a two-sided tolerance-limit factor is used at statistics with $95 \%$ certainty and $68.3 \%$ population. For fewer than 10 measurement data, one-sided tolerance-limit factor is used with $95 \%$ certainty and $95 \%$ population. In our case, the number of samples varied from 8 to 46 , which is equivalent to tolerance factor of 3.14 (for 8 samples) to 1.22 (for 46 samples).

In this work, the correction factors were determined for a set of 40 nuclides based on PIE experiments [5] , [6] and [7] . The correction factors were analyzed for calculation codes from SCALE code system, the results are shown in Table I.

During this analysis, some modifications have been made. As the nuclide ${ }^{103} \mathrm{Rh}$ was not measured in PIE experiments, its correction factor was estimated to be the same as in the case of 
${ }^{109} \mathrm{Ag}$, which is the closest fission product in terms of weight while also having low value of its correction factor. Another problem was caused by isotopes ${ }^{151} \mathrm{Eu}$ and ${ }^{153} \mathrm{Eu}$, which were measured with high deviation and thus leading into negative value of their correcting factor. Their correction factor was therefore set to zero.

Additional analysis was also made for isotopes of gadolinium contained in pins with $\mathrm{Gd}_{2} \mathrm{O}_{3}$ burnable absorber, as these data are not part of PIE experiments. The Gd crosssections were conservatively modified by their $3 \sigma$ deviation from uncertainty library, the impact of modified crosssections was then studied during burnup calculation and correction factors values were determined as a function of burnup, as can be seen in Fig. 2.

\section{CAlCUlation}

The comparison of both methods was made on TVSA-T $\mathrm{Gd}-2 \mathrm{M}+4.76$ fuel assemblies. In burnup calculation, a 2D model of the fuel assembly was used. The fuel pins were divided into 15 groups with respect to $30^{\circ}$ symmetry. The isotopic composition of the fuel was then calculated by TRITON deterministic code from SCALE code system and ENDF/B-VII.1 library in 252-group broadened energy structure.

In criticality calculations, only 47 nuclides were considered in spent fuel composition - this includes 40 nuclides listed in Table I, 6 more isotopes of gadolinium and nuclide ${ }^{16} \mathrm{O}$, which is part of $\mathrm{UO}_{2}$ and $\mathrm{Gd}_{2} \mathrm{O}_{3}$ compounds. The calculations were made on simplified 3D model of spent fuel pool. It consists of lattice filled with fuel assemblies with same symmetry as in burnup calculation. Each assembly is inserted into boron steel hexagonal tube, as is pictured in Fig. 2. The lattice is placed on stainless steel support plate, under which is a layer of moderator and concrete with steel lining. The pool is flooded with clean water with density conservatively assumed as $1.0 \mathrm{~g} / \mathrm{cm}^{3}$.

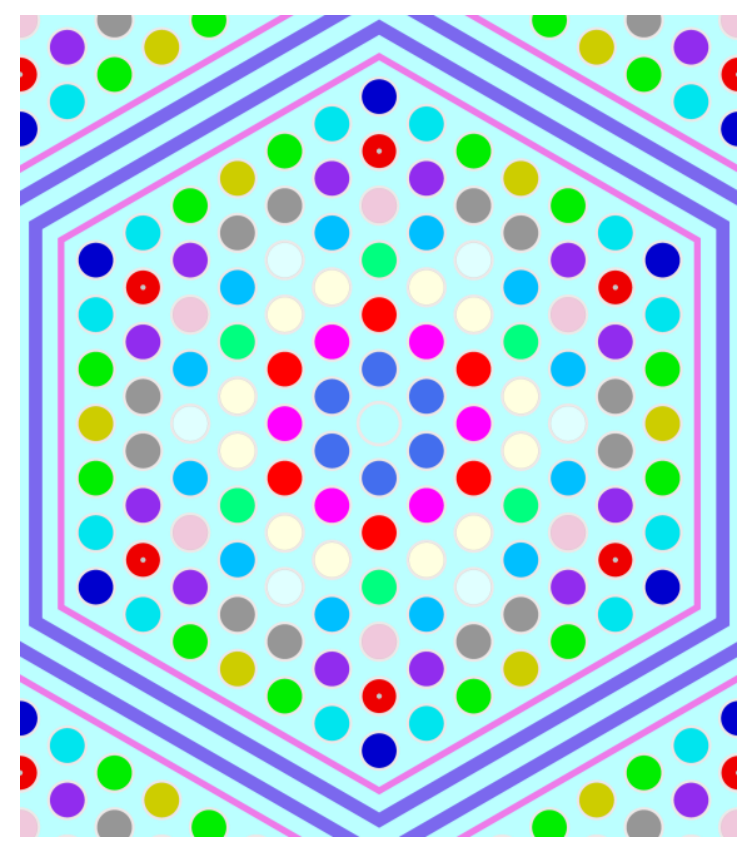

Fig. 1. Detail of fuel assembly in spent fuel pool calculation model.
TABLE I

CORRECTION FACTORS ANALYZED FROM PIE EXPERIMENTS

\begin{tabular}{|c|c|c|c|c|}
\hline Nuclide & $\begin{array}{c}\text { Mean } \\
\text { E/C }\end{array}$ & $\begin{array}{c}\text { Deviation } \\
\text { E/C }\end{array}$ & $\mathrm{CF}$ & $\begin{array}{c}\mathrm{CF} \\
\text { (used) }\end{array}$ \\
\hline Мo-95 & 0.98 & 0.02 & 0.912 & 0.912 \\
\hline Tc-99 & 0.99 & 0.02 & 0.934 & 0.934 \\
\hline Ru-101 & 1.00 & 0.02 & 0.939 & 0.939 \\
\hline Rh-103 & 0.00 & 0.00 & 0.311 & 0.311 \\
\hline Ag-109 & 0.56 & 0.08 & 0.311 & 0.311 \\
\hline Cs-133 & 1.01 & 0.02 & 0.938 & 0.938 \\
\hline Cs-134 & 1.09 & 0.13 & 0.678 & 0.678 \\
\hline Cs-135 & 1.01 & 0.03 & 0.922 & 0.922 \\
\hline Cs-137 & 1.02 & 0.02 & 0.952 & 0.952 \\
\hline $\mathrm{Ce}-140$ & 1.00 & 0.02 & 0.932 & 0.932 \\
\hline $\mathrm{Ce}-142$ & 0.99 & 0.03 & 0.913 & 0.913 \\
\hline Nd-142 & 1.03 & 0.09 & 0.749 & 0.749 \\
\hline Nd-143 & 0.99 & 0.02 & 0.912 & 0.912 \\
\hline Nd-144 & 1.01 & 0.03 & 0.926 & 0.926 \\
\hline Nd-145 & 1.08 & 0.04 & 0.962 & 0.962 \\
\hline Nd-146 & 0.93 & 0.01 & 0.893 & 0.893 \\
\hline Nd-148 & 1.01 & 0.02 & 0.963 & 0.963 \\
\hline $\mathrm{Nd}-150$ & 1.00 & 0.02 & 0.944 & 0.944 \\
\hline Sm-147 & 0.99 & 0.07 & 0.769 & 0.769 \\
\hline Sm-148 & 1.10 & 0.06 & 0.920 & 0.920 \\
\hline Sm-149 & 0.91 & 0.08 & 0.654 & 0.654 \\
\hline Sm-150 & 0.99 & 0.05 & 0.814 & 0.814 \\
\hline Sm-151 & 0.93 & 0.07 & 0.710 & 0.710 \\
\hline Sm-152 & 0.93 & 0.06 & 0.757 & 0.757 \\
\hline Sm-154 & 0.95 & 0.06 & 0.774 & 0.774 \\
\hline Eu-151 & 0.45 & 0.36 & -0.666 & 0.000 \\
\hline Eu-153 & 0.18 & 0.06 & -0.021 & 0.000 \\
\hline Gd-155 & 0.16 & 0.02 & 0.086 & 0.086 \\
\hline U-234 & 0.99 & 0.16 & 0.801 & 0.801 \\
\hline U-235 & 0.97 & 0.06 & 1.048 & 1.048 \\
\hline U-236 & 1.05 & 0.08 & 0.945 & 0.945 \\
\hline U-238 & 1.00 & 0.00 & 1.000 & 1.000 \\
\hline Np-237 & 1.47 & 0.59 & 0.627 & 0.627 \\
\hline $\mathrm{Pu}-238$ & 1.20 & 0.26 & 0.879 & 0.879 \\
\hline $\mathrm{Pu}-239$ & 0.97 & 0.10 & 1.089 & 1.089 \\
\hline $\mathrm{Pu}-240$ & 1.00 & 0.07 & 0.906 & 0.906 \\
\hline $\mathrm{Pu}-241$ & 1.02 & 0.11 & 1.158 & 1.158 \\
\hline $\mathrm{Pu}-242$ & 1.06 & 0.22 & 0.787 & 0.787 \\
\hline Am-241 & 1.02 & 0.04 & 0.880 & 0.880 \\
\hline Am-243 & 0.87 & 0.18 & 0.654 & 0.654 \\
\hline
\end{tabular}

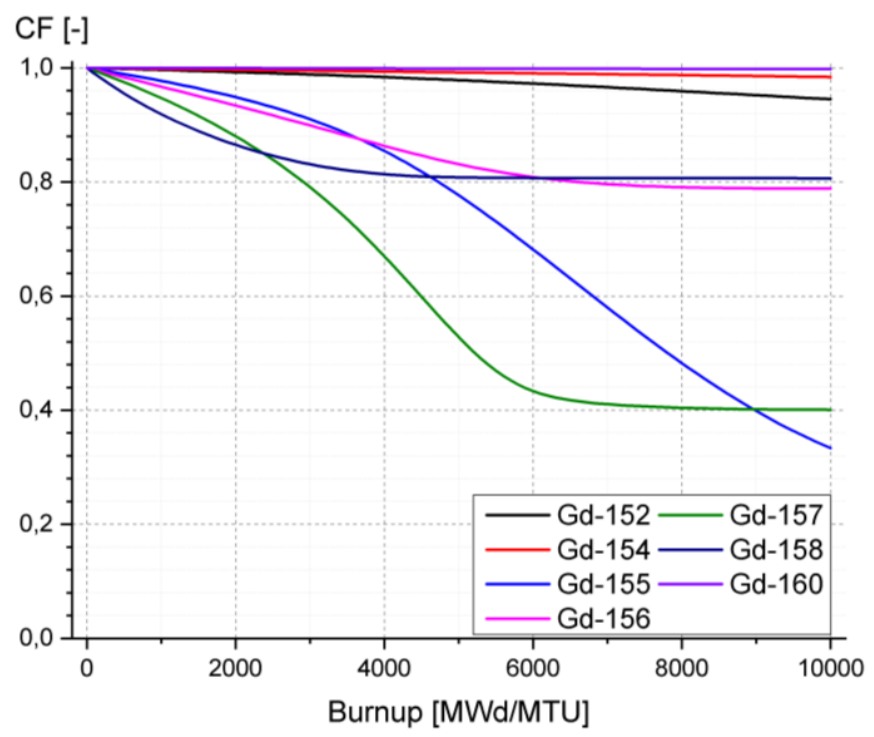

Fig. 2. Correction factors for isotopes of gadolinium in pins with $\mathrm{Gd}_{2} \mathrm{O}_{3}$ burnable absorber as a function of burnup. 


\section{A. Bounding Approach}

In bounding approach, the concentrations of nuclides were adjusted using correction factors CF mentioned above. The criticality calculation was then made for 21 steps of fuel burnup, calculated by KENO-VI code from SCALE system. The results are shown in Fig. 3. The maximum of effective multiplication factor is in this case at $8000 \mathrm{MWd} / \mathrm{MTU}$, with a value of:

$$
k_{\text {eff }}=0.94309 \pm 0.00016 .
$$

As this is the highest achievable $k_{e f f}$ value, it is also a crucial point from the nuclear safety perspective and was therefore investigated further in case of Monte Carlo sampling.

\section{B. Monte Carlo Sampling}

In Monte Carlo sampling, the correction factors were not used. Instead, the concentrations of nuclides were multiplied by a factor from a set of pseudorandom numbers, which were generated with normal distribution based on E/C value and its standard deviation as shown in Table I. Each nuclide in each pin has therefore its own unique concentration, while also satisfying its probability distribution (see Fig. 5).

As the sampling method is more computationally demanding than the standard bounding approach described above, we have analyzed only the case with maximum multiplication factor, which is according to the previous calculation at burnup of $8000 \mathrm{MWd} / \mathrm{MTU}$. A total of 5000 calculation cases were created, from which the first case was sampled in unperturbed state, where nuclide concentrations were multiplied only by mean $\mathrm{E} / \mathrm{C}$ value and the deviations were not considered. All other cases are perturbed, i.e. they were sampled according to the procedure described above.

The samples were calculated in criticality calculation by transportation code KENO-VI from SCALE code system. The results are individual values of multiplication factor $k_{i}$ of sampled cases $i$. The mean value $\bar{k}$, as well as corrected sample standard deviation $s$, of all perturbed cases was determined:

$$
\begin{gathered}
\bar{k}=\frac{1}{n} \sum_{i}^{n} k_{i}, \\
s=\sqrt{\frac{1}{n-1} \sum_{i}^{n}\left(k_{i}-\bar{k}\right)^{2} .}
\end{gathered}
$$

This leads to a final result - the effective multiplication factor of all perturbed cases:

$$
k_{\text {eff }}=0.91374 \pm 0.00542,
$$

which is close to multiplication factor of unperturbed case $k_{0}$ :

$$
k_{0}=0.91872 \pm 0.00013
$$

\section{Bounding approach}

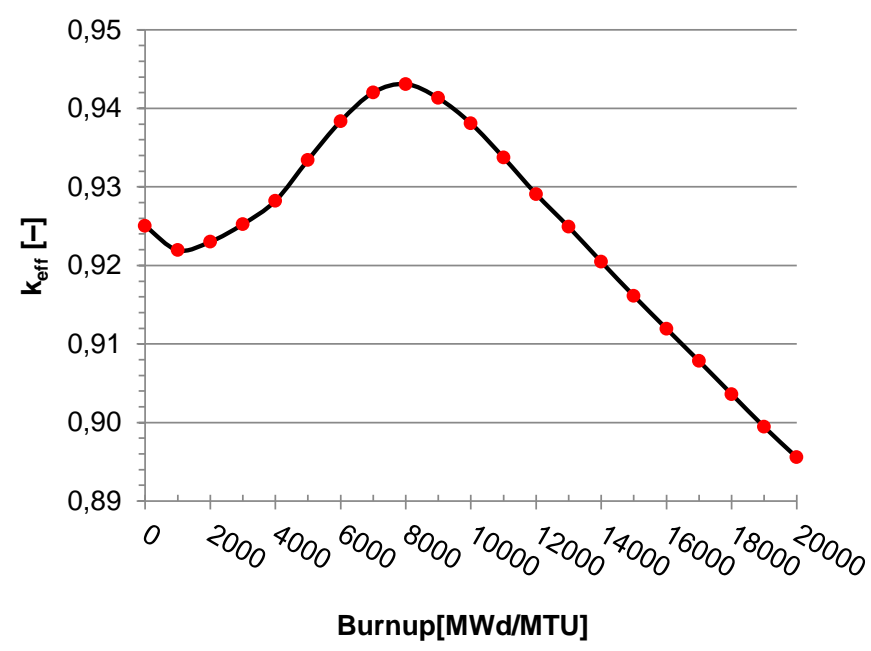

Fig. 3. Multiplication factor based on fuel burnup calculated by bounding approach with correction factors on spent fuel pool model.

\section{Monte Carlo Sampling}
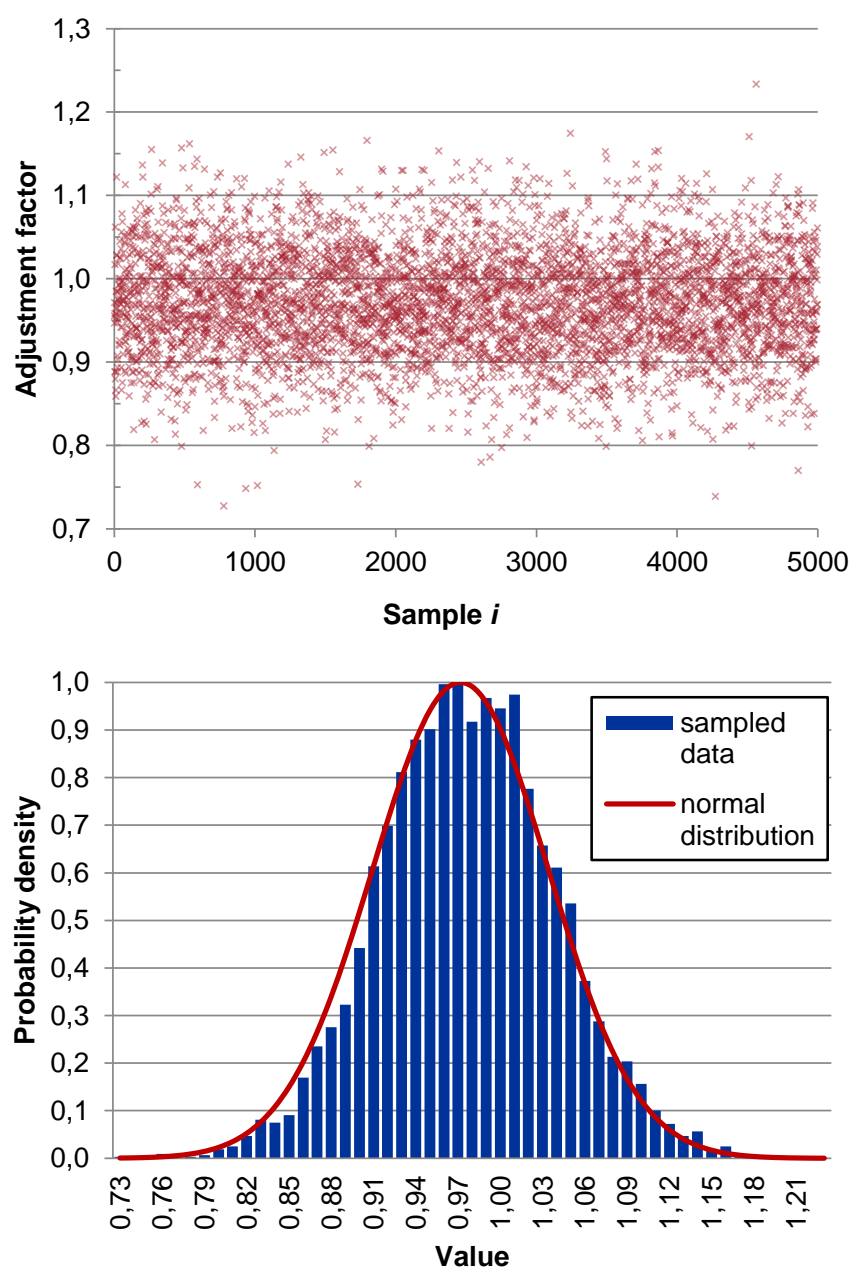

Fig. 4. Example of adjustment factor sampling for U-235 in one of the pins and its probability density function. In this case, the factor was sampled according to normal distribution with mean $\mu=0.97$ and deviation $\sigma=0.06$. 


\section{RESULTS}

The results of both methods can be summarized as follows:

- Bounding approach:

$$
k_{e f f}(\mathrm{BA})=0.94309 \pm 0.00016
$$

- Monte Carlo sampling:

$$
k_{\text {eff }}(\mathrm{MC})=0.91374 \pm 0.00542 \text {. }
$$

In this case, the multiplication factor calculated by bounding approach is higher by 0.02935 , which is about $5.4 \times$ more than the value of the standard deviation of the sampled Monte Carlo tasks. The comparison shows how much conservative the bounding approach is.

The using of Monte Carlo sampling method can reduce the maximum multiplication factor for models where the coefficient is slightly above the legislative limit based on the current conservative burnup credit methodology. This could lead to an alleviation of possible restrictions resulting from the limit exceeding. However, it should be kept in mind that Monte Carlo sampling approach requires a calculation of large number of tasks and is therefore more computationally demanding.

\section{REFERENCES}

[1] P. Haroková, M. Lovecký, “Comparison of bounding approach with correction factors and Monte Carlo sampling for determination of isotopic composition of spent fuel in burnup credit method. ", Škoda JS report Ae19117, 2019 [in Czech].

[2] M. Lovecký, "Comparison of results of spent fuel inventory calculations with ORIGEN-S code with experiments. ", Škoda JS report Ae14561, 2012 [in Czech].

[3] G. Radulescu, I. C. Gauld, G. llas, J. C. Wagner, "An Approach for Validating Actinide and Fission Product Burnup Credit Criticality Safety Analyses - Isotopic Composition Predictions". US NRC Report NUREG/CR-7108, Oak Ridge, 2012.

[4] I. C. Gauld, "Strategies for Application of Isotopic Uncertainties in Burnup Credit”. US NRC Report, NUREG/CR-6811, Oak Ridge, 2003.

[5] L. J. Jardine, "Radiochemical Assays of Irradiated VVER-440 Fuel for Use in Spent Fuel Burnup Credit Activities". LLNL Report, UCRL-TR212202, Livermore, 2005.

[6] Yu. N. Kravchenko, "Benchmark Calculation of Fuel Burnup and Isotope Composition of VVER-440 Spent Fuel". Kurchatov Institue Report, Moscow, 1998.

[7] T. P. Makarova, B. A. Bibichev, V. D. Domkin, "Destructive Analysis of the Nuclide Composition of Spent Fuel of WWER-440, WWER-1000, and RBMK-1000 Reactors". Radiochemistry 50 (2008) 414-426.

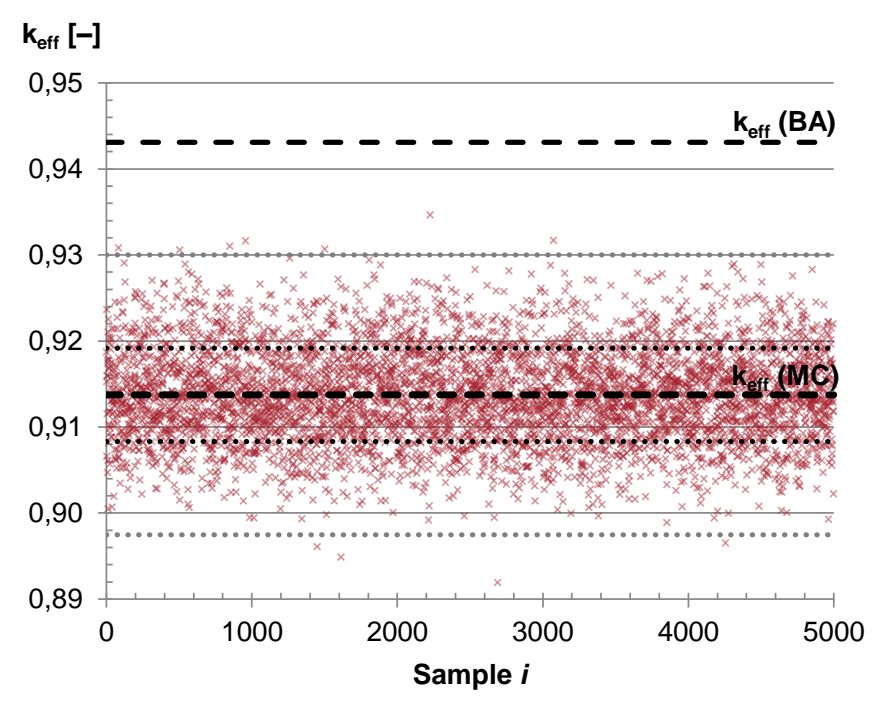

Fig. 5. Comparison of results calculated by bounding approach $-k_{\text {eff }}(\mathrm{BA})$, and Monte Carlo sampling $-k_{\text {eff }}(\mathrm{MC})$, with its standard deviation represented by dotted line. Results of individual samples $k_{i}$ are also shown (represented by red crosses). 